\title{
Hypoxia application in athletes is not doping
}

Dieter Böning

Accepted: 22 October 2009 / Published online: 11 November 2009

(C) Springer-Verlag 2009

\section{Dear Editor,}

As a physiologist, I propose to consider the doping problem from the viewpoint of our discipline. A stay in hypoxia, be it continuous or intermittent, poses a challenge on the regulatory potential of the organism like various other stimuli applied during physical training. This usually leads to improvements of functions after acclimatization if the challenge does not exceed the adaptive capacity of an organism; for a permanent stay, the limit for humans is an altitude of approximately $5,000 \mathrm{~m}$ above sea level. In most athletes, the health problems suggested by Lippi and Franchini (2009) may be prevented by avoiding too rapid or too high ascents to real or artificial altitudes.

In contrast, most doping manipulations including erythropoietin injections and blood infusions disturb the regulation usually securing homeostasis and thus health in the organism. This is different from clinical medicine where these measures are used to replace lost functional properties or regulations. Disturbing the physiological equilibrium can impose risks to individuals, although the incidence of this has not been formally documented. The often proposed abolition of any doping control would exaggerate the risks.

Communicated by Susan Ward.

D. Böning $(\bowtie)$

Sportmedizin, Charité,

Universitätsmedizin Berlin,

Arnimallee 22, 14195 Berlin, Germany

e-mail: dieter.boening@charite.de
The suggestion by Sanchis-Gomar et al. (2009) that intermittent hypoxia after erythropoietin doping increases the reticulocyte number thus influencing the Off score as indirect measure of blood doping (Parisotto et al. 2001) is only based on a small animal experiment and is still somewhat hypothetical. But it raises concern that a rather simple parameter like a score considering only two quantities (hemoglobin concentration and reticulocyte number) in a complex regulatory network might be not fully reliable for a clear decision about doping and thus unnecessarily casts suspicion on an athlete. A possible solution for the problem of effects of hypoxia on such scores is a correction factor discussed by Ashenden et al. (2003); surprisingly this paper is not cited by Sanchis-Gomar et al.

Considering these various aspects, it is not justified to include every treatment with partly equal effects like blood doping and influencing similarly a simple score in the prohibition list.

\section{References}

Ashenden MJ, Gore CJ, Parisotto R, Sharpe K, Hopkins WG, Hahn AG (2003) Effect of altitude on second-generation blood tests to detect erythropoietin abuse by athletes. Haematologica 88:10531062

Lippi G, Franchini M (2009) Intermittent hypoxic training: doping or what? Eur J Appl Physiol (Letter to the Editor)

Parisotto R, Wu M, Ashenden MJ, Emslie KR, Gore CJ, Howe C, Kazlauskas R, Sharpe K, Trout GJ, Xie M (2001) Detection of recombinant human erythropoietin abuse in athletes utilizing markers of altered erythropoiesis. Haematologica 86:128-137

Sanchis-Gomar F, Martinez-Bello VE, Domenech E, Nascimento AL, Pallardo FV, Gomez-Cabrera MC, Vina J (2009) Effect of intermittent hypoxia on hematological parameters after recombinant human erythropoietin administration. Eur J Appl Physiol 107:429-436 